\title{
Antimicrobial Activity of a Tissue Conditioner Combined with a Biocide Polymer
}

\author{
${ }^{1}$ Carina Toda, ${ }^{2}$ Danny Omar Mendoza Marin, ${ }^{3}$ Larissa Santana Rodriguez, ${ }^{4}$ André Gustavo Paleari \\ ${ }^{5}$ Ana Carolina Pero, ${ }^{6}$ Marco Antonio Compagnoni
}

\section{ABSTRACT}

Background: The characteristics of tissue conditioners support microorganism development that can threaten the health of the dentures user.

Purpose: The object of this study was to evaluate the effect on antimicrobial activity, roughness and wettability surface of a tissue conditioners material combined with the antimicrobial polymer poly (2-tert-butilaminoethyl) methacrylate (PTBAEMA).

Materials and methods: Specimens of tissue conditioner (Coe Soft ${ }^{\circledR}$ ) were divided into three groups, according to the concentration of PTBAEMA incorporated (0, 10 and 25\%). Antimicrobial activity was assessed by adherence assay of one of the microorganisms, Staphylococcus aureus, Streptococcus mutans and Candida albicans. Roughness measurements were made using a Mitutoyo SJ-400, and the mean arithmetic roughness values $(\mathrm{Ra})$ obtained were used for the comparisons. The wettability properties were determined by contact angle measurements.

Results: The group containing $25 \%$ of PTBAEMA inhibited totally the $S$. aureus and $S$. mutans biofilm formation. A significant reduction in the $S$. aureus (Kruskal-Wallis, $p=0,001$ ) and S. mutans (Kruscal-Wallis, $p=0,001$ ) count for $10 \%$ PTBAEMA group compared with respective control group. No significant difference was found for $C$. albicans among PTBAEMA groups and control group (ANOVA, $p>0,05$ ). Incorporating 10 and $25 \%$ PTBAEMA increased surface roughness and decreased contact angles (ANOVA and Tukey's post hoc tests, $\alpha=5 \%$ ).

Conclusion: Incorporating 10\% PTBAEMA into tissue conditioner increases wettability and roughness of tissue conditioner surface; and decreases the adhesion of $S$. mutans and $S$. aureus on material surface, but did not exhibit antimicrobial effect against $C$. albicans.

Significance: The PTBAEMA incorporated into tissue conditioner could prevent biofilm formation on elderly patient.

Keywords: Antimicrobial, Biofilm, Polymer, Roughness, Tissue conditioner, Wettability.

\footnotetext{
${ }^{1-6}$ Department of Dental Materials and Prosthodontics Araraquara Dental School, UNESP_São Paulo State University, Araraquara, São Paulo, Brazil

Corresponding Author: Marco Antonio Compagnoni Professor, Department of Dental Materials and Prosthodontics Araraquara Dental School, UNESP_São Paulo State University, Araraquara, São Paulo, Brazil, Phone: +551633016411, e-mail: compagno@foar.unesp.br
}

How to cite this article: Toda C, Marin DOM, Rodriguez LS, Paleari AG, Pero AC, Compagnoni MA. Antimicrobial Activity of a Tissue Conditioner Combined with a Biocide Polymer. J Contemp Dent Pract 2015;16(2):101-106.

Source of support: Nil

Conflict of interest: None declared

\section{INTRODUCTION}

The use of tissue conditioners has been recommended to recover the denture base that is in contact with oral mucosa. The principal use of these materials is to treat and condition injured and/or postsurgery tissues in patients with immediate complete dentures. When previously used, their resilient characteristics provided patient comfort, reduced the friction of the complete denture and avoided the transmission of strength to the residual ridge. Although this is common practice, it is also a suitable environment for the propagation of oral microorganisms and biofilm formation, which can lead to the appearance of denture stomatitis. ${ }^{1}$

Denture stomatitis, also known as Candida infection, is a multifactorial etiology disease that is mainly caused by Candida albicans. Previous studies have also shown the prevalence of other species of microorganism on the inner surface of complete dentures. Streptococcus mutans and Staphylococcus aureus are also responsible for denture stomatitis. ${ }^{2,3}$

Several studies have investigated the addition of antimicrobial agents into denture material to reduce or to avoid microorganism development on the surface of the prostheses material. ${ }^{4-8}$ Others have added antimicrobial agents to tissue conditioners., ${ }^{9,10}$

Poly (2 tert-butylaminoethyl) methacrylate (PTBAEMA) is a polycationic polymer that acts as a substitute for low molecular weight biocides. It works on the permeability of the microorganism membrane cell, causing damage and even death. ${ }^{11}$ The polymer provides the advantage of low toxicity and is documented as causing no bacterial resistance. ${ }^{8,11,12}$ In a previous report, PTBAEMA was successfully incorporated into polyethylene or stainless steel surfaces. ${ }^{11,13}$ In addition, the polymer has also exhibited highly antimicrobial properties against Escherichia coli and S. aureus ${ }^{11,13}$ and S. mutans in denture base resin. Marra et $\mathrm{al}^{7}$ 
also observed antimicrobial properties against $S$. mutans and $S$. aureus when incorporating PTBAEMA in denture base resin, with no activity against $C$. albicans.

Paleari et $\mathrm{al}^{8}$ found the presence of amino groups when TBAEMA was incorporated into the denture base resin. The literature confirms that polymers functionalized with the association between pendent amino groups and high antimicrobial activities. The presence of amino groups caused the disorganization of the bacterial membrane and eventually, its death. ${ }^{6,7}$

Thus, tissue conditioners could possibly exhibit activity against oral microorganisms after the incorporation of PTBAEMA into the material. The literature reveals that polymers functionalized with the association between pendent amino groups and high antimicrobial activities. The presence of amino group caused the disorganization of the bacterial membrane and, eventually, its death. ${ }^{6,7,12}$

The aim of the present study was to assess the effect of a tissue conditioner material, combined with the antimicrobial polymer poly (2-tert-butilaminoethyl) methacrylate (PTBAEMA), on antimicrobial activity, roughness and wettability surface. The null hypothesis tested was that the incorporation of PTBAEMA would have no effect on the roughness or wettability and would inhibit the formation of S. aureus, S. mutans and C. albicans biofilm.

\section{MATERIALS AND METHODS}

\section{Specimen Fabrication}

After conducting a pilot study, it was determined that 27 disks ( $15 \mathrm{~mm}$ in diameter and $3 \mathrm{~mm}$ thick) of a tissue conditioner material (Coe Soft GC America Inc, USA) would be produced and divided into three groups, $(n=9)$, according to the PTBAEMA incorporation: $\%$ (control); 10 and $25 \%^{9}$ (Table 1 ).

A metal mold was used to obtain disk-shaped objects of the tissue conditioner material, which were placed between two glass slides. After the polymerization, all specimens were presterilized using ultraviolet light and the surface roughness and contact angle were measured.

\section{Surface Roughness Measurements}

The roughness of the surface was measured using a profilometer (Mitutoyo SJ-400, Mitutoyo Corporation, Tokyo, Japan) with resolution of $0.01 \mu \mathrm{m}$, at a stylus speed of $0.5 \mathrm{~mm} / \mathrm{s}$, a cut-off length of $2.4 \mathrm{~mm}$, and a diamond stylus tip radius of $5 \mu \mathrm{m}$. This method was conducted by scanning a diamond stylus across the surface under a constant load and then computing the numeric values representing the roughness of the profile as $\mathrm{Ra}(\mu \mathrm{m})$. The
Table 1: Mean and standard deviation values of roughness and contact angle with 0, 10 and 25\% PTBAEMA incorporated. The same letters represent statistical similarity (ANOVA and Tukey's post hoc tests, $\alpha=5 \%$ )

\begin{tabular}{llll}
\hline & $0 \%$ & $10 \%$ & $25 \%$ \\
\hline Roughness & $3.79( \pm 0.7)^{\mathrm{a}}$ & $5.66( \pm 0.64)^{\mathrm{b}}$ & $5.40( \pm 0.69)^{\mathrm{b}}$ \\
Contact angle & $58.6( \pm 5.3)^{\mathrm{A}}$ & $49.5( \pm 2.9)^{\mathrm{B}}$ & $48.9( \pm 1.6)^{\mathrm{B}}$ \\
\hline
\end{tabular}

Identical letters denote no significant differences among groups. Different letters denote significant differences among groups

Ra value describes the overall roughness of a surface and is defined as the arithmetic mean value of all absolute distances of the roughness profiles from the center line within the measuring length. ${ }^{14}$

\section{Contact Angle Measurements Method}

The contact angle measurement method was used to characterize the surface wettability. A liquid drop was placed onto a substrate using a microsyringe. Droplets of deionized water (volume of $\sim 1.0 \mu \mathrm{l}$ ) were used to measure the contact angle. An automated goniometer (Ramé-hart 200, Ramé-hart instrument co, Netcong, New Jersey, USA), connected to a computer, was used to measure the contact angles produced by the droplets on the specimens. A charge-coupled Device (CCD) camera was used to record the image of the droplets on the surface and the analyses were performed using DROP image Standard software (Ramé-hart instrument co, Netcong, New Jersey, USA). ${ }^{14}$

These measurements were carried out optically with an accuracy of $\pm 1^{\circ}$. Three drops were placed at different random locations on each sample and the mean value was then determined. This procedure took into account the possible non-uniformity of the surface probed by the contact angle. All of these experiments were carried out by the same operator in a controlled temperature $\left(25 \pm 1^{\circ} \mathrm{C}\right)$.

\section{Adherence Assay}

Three standard strain microorganisms were tested: S. aureus ATCC 25923; S. mutans ATCC 25175 and C. albicans ATCC 90028. Microbial suspensions were obtained from single colonies isolated on agar plates, which were inoculated in the appropriate broth (overnight cultures) at $37^{\circ} \mathrm{C}$. S. mutans was grown in Mitis Salivarius Bacitracin (Difco) whereas C. albicans was grown in Sabouraud Dextrose Agar (HIMEDIA) and the S. aureus strain grew in Tryptic Soy Broth (HIMEDIA). Microbial suspensions were adjusted to $10^{7} \mathrm{cfu} / \mathrm{ml}$ by adjusting the optical density to $600 \mathrm{~nm}$ for bacterium and $540 \mathrm{~nm}$ for fungi with a spectrophotometer (Biophotometer plus; Eppendorf Hauppauge, NY, USA). 


\section{Antimicrobial Activity}

Each specimen was inoculated with one of the tested microorganisms (S. aureus, S. mutans and C. albicans) in presterilized, 12-well polystyrene flat-bottomed microtiter plates, with $2 \mathrm{ml}$ of standard cell suspension $\left(10^{7} \mathrm{cfu} / \mathrm{ml}\right)$, in an orbital shaker for 1.5 hours at $37^{\circ} \mathrm{C}$ and $75 \mathrm{rpm}$. After the adhesion phase, each sample was washed twice with $2 \mathrm{ml}$ phosphate-buffered saline (PBS, pH 7.2). To promote biofilm growth, $2 \mathrm{ml}$ of the appropriate fresh broth was added to each well and incubated at $37^{\circ} \mathrm{C}$ and $75 \mathrm{rpm}$ for 48 hours under aerobic conditions (S. aureus and C. albicans) or anaerobic conditions (S. mutans). After incubation, each specimen was gently washed twice with PBS and transferred to a sterile tube with $4.5 \mathrm{ml}$ sterile PBS and then vortexed vigorously for 1 minute to remove adherent colonies. Serial dilutions were made for each specimen solution and $10 \mu \mathrm{l}$ of each $10^{-7}-10^{-1}$ solution was plated in duplicate on three selective media: Mannitol Salt Agar for S. aureus; Mitis Salivarius Bacitracin for S. mutans and Sabouraud Dextrose Agar containing $5 \mu \mathrm{g} / \mathrm{ml}$ of chloramphenicol for C. albicans. After 48 hours of incubation at $37^{\circ} \mathrm{C}$ under aerobic and anaerobic conditions, the bacterial and yeast colony counts of each plated specimen were quantified. The colony forming units per millimeter $(\mathrm{cfu} / \mathrm{ml})$ were then calculated. ${ }^{6,7}$

No homogeneity of variances was observed for the three species assessed (Levene test, $\mathrm{p}<0.05$ ). Consequently, no parametric tests were performed. The S. aureus and S. mutans results were compared using the Kruskal-Wallis test and the $C$. albicans results were compared using the ANOVA test. All analyses were performed with $\alpha=0.05$.

\section{RESULTS}

Table 1 displays the effect of PTBAEMA incorporation into tissue conditioner specimens on the surfaces by roughness and wettability.

Table 2 displays the results obtained for the groups with 0,10 and $25 \%$ of PTBAEMA in the tissue conditioner specimens and each microorganism.

The roughness data and the mean contact angle values of each group were compared by one-way analysis of variance (ANOVA), followed by Tukey's post-hoc test, with the level of significance set at 5\% (Table 1).

The statistical analysis demonstrated that the incorporation of PTBAEMA increased the roughness of tissue conditioner surfaces with significant differences $(\mathrm{p}<$ 0.001). No differences were found between the groups PTBAEMA 10\% and PTBAEMA 25\% (Tukey's test, $\mathrm{p}=$ 0.685) (Table 1).
Table 2: Mean (standard deviation) of the number of log (CFU/ml) for Staphylococcus aureus and Staphylococcus. mutans (KruskalWallis test, $p=0.001$ ) and for Candida albicans (ANOVA test, $p>0.05$ )

\begin{tabular}{llll}
\hline Groups & $0 \%$ & $10 \%$ & $25 \%$ \\
\hline S. aureus & $6.51( \pm 0.36)^{\mathrm{a}}$ & $2.77( \pm 2.14)^{\mathrm{b}}$ & $0.00( \pm 0.00)^{\mathrm{b}}$ \\
S. mutans & $3.44( \pm 0.64)^{\mathrm{A}}$ & $0.80( \pm 1.65)^{\mathrm{B}}$ & $0.00( \pm 0.00)^{\mathrm{B}}$ \\
C. albicans & $5.14( \pm 0.24)^{\mathrm{C}}$ & $5.22( \pm 0.13)^{\mathrm{C}}$ & $5.26( \pm 0.20)^{\mathrm{C}}$ \\
\hline
\end{tabular}

Identical letters denote no significant differences among groups. Different letters denote significant differences among groups

Furthermore, the incorporation of PTBAEMA made the material surfaces more wettable. Table 1 displays the contact angle measurements obtained for the groups with 0, 10 and 25\% PTBAEMA. Significant differences ( $p<0.05$ ) were detected between the groups (Group 0\% $=58.6^{\circ} \pm 5.3^{\mathrm{A}}$, group $10 \%=49.5^{\circ} \pm 2.9^{\mathrm{B}}$, group $25 \% 48.9^{\circ}$ $\left.\pm 1.6^{\mathrm{B}}\right)$ (Table 1$)$.

Significant antimicrobial activity was observed with specimens containing 10\% of PTBAEMA in comparison to the corresponding control groups (Kruskal-Wallis Test, $\mathrm{p}<0.05$ ) in terms of $S$. aureus and $S$. mutans biofilm formation. In addition, the 25\% PTBAEMA group exhibited no viable biofilm bacteria cells (Table 2). However, there was no significant difference between the groups for the C. albicans viable biofilm cells (Control group: $5.14 \pm 0.24$; group 10\%: $5.22 \pm 0.13$; group 25\%: $5.26 \pm 0.20$ ) (ANOVA test, $\mathrm{p}>0.005)$.

\section{DISCUSSION}

The microbiological assay in the present study showed that the group containing 10\% PTBAEMA significantly reduced the number of viable cells of $S$. aureus and $S$. mutans on the specimens' surfaces when compared with the control group ( $0 \%$ PTBAEMA). Complete inhibition of $S$. aureus and $S$. mutans biofilm formation was observed in the group with 25\% PTBAEMA. In 2006, Seyfriedsberger also found antimicrobial activity of PTBAEMA incorporated into polyethylene surfaces. The author observed a reduction of the CFU/ml of $S$. aureus to zero after 24 hours of contact with a polyethylene surface with PTBAEMA.

Several studies have confirmed that PTBAEMA exhibits antimicrobial activity. Ignatova et $\mathrm{al}^{13}$ observed a reduction of S. aureus adsorption by $99.9 \%$. In 2011, Paleari et $\mathrm{al}^{8}$ concluded the incorporation of TBAEMA results in the presence of potentially antimicrobial amino groups on specimen surfaces of an acrylic resin. Compagnoni et $\mathrm{al}^{6}$ demonstrated that the incorporation of PTBAEMA into acrylic resins decreased the adhesion of $S$. mutans and $S$. aureus biofilms on denture surfaces, but did not exhibit an antimicrobial effect against C. albicans. Marra et $\mathrm{al}^{7}$ reported that acrylic resin combined with 10 and 25\% PTBAEMA exhibited significant antimicrobial acti- 
vity against $S$. aureus and $S$. mutans biofilms, but was inactive against the $C$. albicans biofilm. The mechanism of PTBAEMA antimicrobial activity was explained by Lenoir et al. ${ }^{12}$ The polymer is a polycationic substance that contains pendant amino groups which act as an efficient contact biocide. The divalent cations $\mathrm{Ca}^{2+}$ and/or $\mathrm{Mg}^{2+}$ that cross-bridge the outer membrane of the bacteria are replaced by the charged amino groups of PTBAEMA, followed by membrane disorganization and lysis of the cells.

The present study documented that the biofilm C. albicans development on tissue conditioner surface revealed no differences between the control group and the 10\% PTBAEMA and 25\% PTBAEMA groups, confirming the null hypothesis for this microorganism. Similar results were found by Marra et $\mathrm{al}^{7}{ }^{7}$ who studied the biofilm formation of S. aureus, S. mutans and C. albicans on acrylic resin surfaces with different PTBAEMA concentrations and demonstrated that the CFU/ $\mathrm{ml}$ of $C$. albicans did not decrease with higher PTBAEMA concentrations.

Despite these results, several studies have explained that the oral cavity is not colonized and infected by a single living cell, but rather as a complex structured microbial community. There are more than 500 species of microorganisms that comprise the oral flora with a pellicle, dynamic temperature, nutrition, the substratum type and saliva all involved in the biofilm formation. ${ }^{15-17}$ In vivo, the presence of saliva conditioning films seemed to favor the initial adherence of bacteria, followed by epithelial cells and yeast cells admixed in an extracellular matrix. ${ }^{16}$ In vitro, Pereira et al ${ }^{18}$ used scanning electron microscopy and reported that the multi-species biofilm of C. albicans, S. aureus and S. mutans were formed by yeast cells and aggregated bacteria on the substratum, with abundant extracellular matrix. The single species biofilm exhibited a few cells on the substratum and a decreased extracellular matrix.

A number of authors have shown that S. mutans increased Candida biofilm formation. ${ }^{15-19}$ During initial colonization, a synergistic beneficial process operates between S. mutans and C. albicans over short periods. After competition for longer periods, S. mutans is outcompeted by C. albicans. ${ }^{19}$

Ishijima et $\mathrm{al}^{20}$ suggested that $S$. Salivarius K12 may inhibit the process of adhesion to denture acrylic by mechanisms not associated with antimicrobial activity. Significant reductions of $S$. mutans biofilm were observed in the present study. It is possible that an alteration of the structure biofilm on material surface with PTBAEMA could be found in a mixed microorganism assay with C. albicans and S. mutans biofilm.
The present study also assessed the physical and microbiological influence of PTBAEMA incorporation into a tissue conditioner with different concentrations, through the roughness and wettability measurement method. These factors are directly related to the initial phase of microorganism adhesion. The antimicrobial activity of PTBAEMA incorporated against the biofilm development of $C$. albicans, S. mutans and S. aureus were also studied.

The results showed that the incorporation of PTBAEMA into a tissue conditioner increased the surface roughness. These results were also found by Pero et $\mathrm{al}^{21}$ when the author incorporated PTBAEMA into an acrylic resin and observed a significant increase in surface roughness. This aspect can interfere with microbial colonization and the maturation of biofilm on denture surfaces, ${ }^{22,23}$ since the initial adhesion of microorganisms is directly influenced by the surface roughness. ${ }^{24}$

According to Teughels et al, ${ }^{17}$ the surface roughness on the biofilm formation is impacted by several factors: the initial adhesion of bacteria starts where they are sheltered against shear forces; roughening of the surface increases the area available for adhesion; a rough surface is more difficult to clean.

The mean values for tissue conditioner roughness ${ }^{25}$ ranged from 2.8 to $4.2 \mu \mathrm{m}$. Kang et $\mathrm{al}^{26}$ reported that roughness does not interfere with the C. albicans biofilm adhesion on tissue conditioner surfaces when there is a controlled roughness ( $\mathrm{Ra}<\sim 1.5 \mu \mathrm{m}$ ). The results of the present study were within the acceptable limits. Moreover, Pavan et al ${ }^{27}$ suggested that roughness is not the main factor in microorganism adhesion.

The results of contact angle measurements on the surface of tissue conditioners are in agreement with previous studies. ${ }^{6,21}$

As found by Compagnoni et $\mathrm{al}^{6}$ and Pero et $\mathrm{al}^{21}$ the incorporation of $10 \%$ of PTBAEMA into tissue conditioners modifies two properties of this surface. Roughness was increased while the contact angle was reduced, making the surface more hydrophilic. This property makes the surface more susceptible to biofilm formation. ${ }^{17}$

Yoshijima et $\mathrm{al}^{28}$ suggested that hydrophilic coating of denture surfaces could reduce the adherence of relatively hydrophobic hyphal fungi, particularly C. albicans, which is the main microorganism associated with denture stomatitis. These findings demonstrate that the exact mechanism by which the adhesion of microorganisms occurs is dependent on other factors related to the substrate, such as surface free energy, surface tension and electrostatic interactions. ${ }^{6,23,29-31}$

Within the limitations of the present study, favorable outcomes were observed indicating that PTBAEMA could 
be used in association with tissue conditioners, since Streptococcus sp are considered a fundamental building block of initial oral biofilms and $S$. aureus produces substantial morbidity and mortality in hemodialysis patients. ${ }^{32,33}$

In conclusion, the PTBAEMA incorporated in tissue conditioners increased the roughness of surfaces and the wettability. Significant antimicrobial activity against S. aureus and S. mutans was recorded when 10 and $25 \%$ of PTBAEMA were added to the material, but there was no significant effect on the C. albicans biofilm formation.

The results demonstrated a potential use of PTBAEMA to improve the oral health of elderly patients. Currently, there is no research exploring this antimicrobial material for prosthesis. Further, studies should be conducted to assess the cytotoxicity of PTBAEMA.

\section{ACKNOWLEDGMENTS}

The authors would like to thank FAPEAM for financial support (Grant number N. 0274/2012). The authors declare no potential conflicts of interest with respect to the authorship and/or publication of this article.

\section{REFERENCES}

1. Alcantara CS, Macedo AFC, Gurgel BCV, Jorge JH, Nepplenbroek KH, Urban VM. Peel bond strength of resilient liner modified by the addition of antimicrobial agentes to dentine base acrylic resin. J Appl Oral Sci 2012;20(6):607-612.

2. Baena-Monroy T, Moreno-Maldonado V, Franco-Mart_inez F, Aldape-Barrios B, Quindos G, Sanchez-Vargas LO. Candida albicans, Staphylococcus aureus and Streptococcus mutans colonization in patients wearing dental prosthesis. Med Oral Patol Oral Cir Bucal 2005;10(Suppl 1):E27-E39.

3. Sumi Y, Kagami H, Ohtsuka Y, Kakinoki Y, Haruguchi Y, Miyamoto H. High correlation between the bacterial species in denture plaque and pharyngeal microflora. Gerodontol 2003;20(2):84-87.

4. Monteiro DR, Silva S, Negri M, Gorup LF, de Camargo ER, Oliveira R, Barbosa DB, Henriques M. Antifungal activity of silver nanoparticles in combination with nystatin and chlorhexidine digluconato against Candida albicans and Candida glabrata biofilms. Mycoses 2013; Jun 17;56(6):672-680.

5. Rodriguez LS, Paleari AG, Giro G, Oliveira Junior NM, Pero AC, Compagnoni MA. Chemical characterization and flexural strength of a denture base acrylic resin with monomer 2 tertbutylaminoethyl methacrylate. J Prosthodont 2013;22(4): 292-297.

6. Compagnoni MA, Pero AC, Ramos SM, Marra J, Paleari AG, Rodriguez LS. Antimicrobial activity and surface properties of an acrylic resin containing a biocide polymer. Gerodontol 2012;Dec 20;31(3):220-226.

7. Marra J, Paleari AG, Rodriguez LS, Leite AR, Pero AC, Compagnoni MA. Effect of an acrylic resin combined with an antimicrobial polymer on biofilm formation. J Appl Oral Sci 2012;20(6):643-648.

8. Paleari AG, Marra J, Pero AC, Rodriguez LS, Ruvolo-Filho A, Compagnoni MA. Effect of incorporation of 2-tert-butylami- noethyl methacrylate on flexural strength of a denture basee acrylic resin. J App Oral Sci 2011;19(3):195-199.

9. Chopde N, Pharande A, Khade MN, Khadtare YR, Shah SS, Apratim A. Source in vitro antifungal activity of two tissue conditioners combined with nystatin, miconazole and fluconazole against Candida albicans. J Contemp Dent Pract 2012 Sep 1;13(5):695-698.

10. Uchimaru M, Sakai T, Moroi R, Shiota S, Shibata Y, Deguchi M, Sakai H, Yamashita Y, Terada Y. Antimicrobial and antifungal effects of tissue conditioners containing a photocatalyst. Dent Mater J 2011;30(5):691-699. Epub 2011 Sep 23.

11. Seyfriedsberger G, Rametsteiner K, Kern W. Polyethylene compounds with antimicrobial surface properties. Euro Polym J 2006;42:3383-3389.

12. Lenoir $S$, Pagnoulle $C$, Galleni $M$, Compère $P$, Jérôme R, Detrembleur C. Polyolefin matrixes with permanent antibacterial activity: preparation, antibacterial activity, and action mode of the active species. Biomacromolecules 2006; 7(8):2291-2296.

13. Ignatova M, Voccia S, Gilbert B, Markova N, Cossement D, Gouttebaron R, Jêrôme R, Jêrôme C. Combination of electrografting and atom-transfer radical polymerization for making the stainless steel surface antibacterial and protein antiadhesive. Langmuir 2006;22(1):255-262.

14. Zissis AJ, Polyzois GL, Yannikakis SA, Harrison A. Roughness of denture materials: a comparative study. Int J Prosthodont 2000;13(2):136-140.

15. Pereira-Cenci T, Cury AADB, Cenci MS, Rodrigues-Garcia RC. In vitro Candida colonization on acrylic resins and denture liners: influence of surface free energy, roughness, saliva, and adhering bacteria. Int J Prosthodont 2007;20(3): 308-310.

16. Avon SL, Goulet JP, Deslauriers N. Removable acrylic resin disk as a sampling system for study of denture biofilms in vivo. J Prosth Dent 2007;97(1):32-38.

17. Teughels W, Assche NV, Sliepen I, Quirynem M. Effect of material characteristics and/or surface topography on biofilm development. Clin Oral Impl Res 2006;17(Suppl 2):68-81.

18. Pereira CA, Romeiro RL, Costa ACBP, Machado AKS, Junqueira JC, Jorge AOC. Susceptibility of Candida albicans, Staphylococcus aureus and Streptococcus mutans biofilms to photodynamic inactivation: an in vitro study. Lasers Med Sci 2011;26(3):341-348.

19. Brusca MI, Irastorza RM, Cattoni DI, Ozu M, Chara O. Mechanism of interaction between Candida albicans and Streptococcus mutans: an experimental and mathematical modeling study. Acta Odontol Scand 2013;71(3-4):416-423.

20. Ishijima SA, Hayama K, Burton JP, Reid G, Okada M, Matsushita Y, Abe S. Effect of Streptococcus salivarius k12 on the in vitro growth of Candida albicans and its protective effect in an oral candidiasis model. Appl En Microbiology 2012;78(7):2190-2199.

21. Pero AC, Ignacio J, Giro G, Mendonza-Marin DO, Paleari AG, Compagnoni MA. Surface properties and color stability of an acrylic resin combined with and antimicrobial polymer. Rev Odontol UNESP 2013;Jul-Aug 42(4):1-6.

22. Cunha TR, Regis RR, Bonatti MR, Souza RF. Influence of incorporation of fluoroalkyl methacrylates on roughness and flexural strength of a denture base acrylic resin. J Appl Oral Sci 2009;17(2):103-107.

23. Minage S, Miyake $Y$, Inagaki K, Tsuru H, Suginaka H. Hydrophobic interaction in Candida albicans and Candida tropicalis adherence to various denture base resin materials. 
Infection and Immunity 1985 Jan;46(1):11-14.

24. Kolenbrander PE, Andersen RN, Blehert DS, Egland PG, Foster JS, Palmer RJ Jr. Communication among oral bacteria. Microbiol Mol Biol Rev 2002;66(3):486-505.

25. Gedik H, Özkan YK. The effect of surface roughness of silicone-based resilient liner materials on the adherence of Candida albicans and inhibition of Candida albicans with differents desinfectants. Oral Health Prev Dent 2009;7(4):347-353.

26. Kang SH, Lee HJ, Hong SH, Kim KH, Kwon TY. Influence of surface characteristics on the adhesion of Candida albicans to various denture lining materials. Acta Odontol Scand 2013;71(1):241-248.

27. Pavan S, dos Santos PH, Arioli Filho JN, Spolidorio DMP. Colonization of soft lining materials by micro-organisms. Gerodontol 2010;27(3):211-216.

28. Yoshijima Y, Murakami K, Kayama S, Liu D, Hirota K, Ichikawa T. Effect of substrate surface hydrophobicity on the adherence of yeast and hyphal Candida. Mycoses 2010;53(3):221-226.
29. Zamperini CA, Machado AL, Vergani CE, Pavarina AC, Giampaolo ET, da Cruz NC. Adherence in vitro of Candida albicans to plasma treated acrylic resin. Effect of plasma parameters, surface roughness and salivary pellicle. Arch Oral Biol 2010;55(10):763-770.

30. Park SE, Blissett R, Susarla SM, Weber HP. Candida albicans adherence to surface-modified denture resin surfaces. J Prosthodont 2008;17(5):365-369.

31. Klotz SA, Drutz DJ, Zajic JE. Factors governing adherence of Candida species to plastic surfaces. Infec Immun 1985;50(1): 97-101.

32. Chalmers NI, Palmer RJ Jr, Cisar JO, Kolenbrander PE. Characterization of a Streptococcus sp.Veillonella sp. community micromanipulated from dental plaque. J Bacteriol 2008;190(24):8145-8154

33. Balaban N, Gov Y, Bitler A, Boelaert JR. Prevention of Staphylococcus aureus biofilm on dialysis catheters and adherence to human cells. Kidney Int 2003;63(1): 340-345. 